\title{
In Silico Study of Gaseous Air Pollutants Effects on Human Atrial Tissue
}

\author{
Catalina Tobón ${ }^{1}$, Diana C Pachajoa ${ }^{2}$, Juan P Ugarte ${ }^{3}$, Javier Saiz ${ }^{4}$ \\ ${ }^{1}$ MATBIOM, Universidad de Medellín, Medellín, Colombia \\ ${ }^{2} \mathrm{GI}{ }^{2} \mathrm{~B}$, Instituto Tecnológico Metropolitano, Medellín, Colombia \\ ${ }^{3}$ GIMSC, Universidad de San Buenaventura, Medellín, Colombia \\ ${ }^{4} \mathrm{CI}^{2} \mathrm{~B}$, Universitat Politècnica de València, Valencia, España
}

\begin{abstract}
Exposure to gaseous air pollutants such as carbon monoxide (CO), nitric oxide ( $\mathrm{NO}$ ) and sulfur dioxide $\left(\mathrm{SO}_{2}\right)$ promotes the occurrence of cardiac diseases. Investigations have shown that $\mathrm{CO}$ and $\mathrm{SO}_{2}$ block the calcium channel ( $\left.I_{\text {CaL }}\right)$ of myocytes. The $\mathrm{SO}_{2}$ also increases the sodium channel $\left(I_{N a}\right)$, the transient outward $\left(I_{t o}\right)$ and inward rectifying $\left(I_{K I}\right)$ potassium currents. The NO blocks $I_{N a}$ and increases $I_{C a L}$. We developed concentrationdependent equations to simulate the gaseous pollutants effects on the ionic currents. They were incorporated in the Courtemanche model of human atrial cell and in a 2D tissue model. A train of 10 stimuli was applied. The action potential duration (APD) was measured. S1-S2 cross-field protocol was applied to initiate a rotor. The $\mathrm{CO}$ and $\mathrm{SO}_{2}$ concentrations from 0 to $1000 \mathrm{uM}$ and NO concentration from 0 to $500 \mathrm{nM}$ were implemented. Six concentration combinations were simulated (cases 1 to 6). The gaseous air pollutants caused an APD shortening and loss of plateau phase of the action potential in a fraction that increases as the pollutant concentration increases. When the highest concentration was applied, the APD decreased by $81 \%$. In the $2 D$ model, from case 4 conditions it was possible to generate rotor, propagating with high stability. These results show pro-arrhythmic effects of gaseous air pollutants.
\end{abstract}

\section{Introduction}

Air pollution can produce alterations in health, affecting the quality of life of the population and the degradation of ecosystems. According to the WHO, environmental pollution is responsible for around 4.3 million premature deaths each year [1]. Exposure to gaseous air pollutants like carbon monoxide ( $\mathrm{CO})$, nitric oxide (NO) and sulfur dioxide $\left(\mathrm{SO}_{2}\right)$ promotes the occurrence of cardiac diseases. There are studies showing that $\mathrm{CO}$ and $\mathrm{SO}_{2}$ block the calcium channel $\left(\mathrm{I}_{\mathrm{CaL}}\right)$ of myocytes [2] [3]. The $\mathrm{SO}_{2}$ also increases the sodium channel $\left(\mathrm{I}_{\mathrm{Na}}\right)$, the transient outward $\left(\mathrm{I}_{\mathrm{to}}\right)$ and inward rectifying $\left(\mathrm{I}_{\mathrm{K} 1}\right)$ potassium currents [3][6]. The NO blocks I $\mathrm{Na}$ and increases ICaL [7], [8].

The aim of this work is to study the effects of the gaseous pollutants at different concentrations on human atrial tissue, using computational simulation.

\section{Methods}

Based on experimental data, we developed concentration-dependent equations to simulate the gaseous pollutants effects on the ionic currents. They were incorporated in a model of human atrial cell and in a 2D tissue model.

\subsection{Human atrial cell model}

The Courtemanche model [9] to simulate the atrial action potential was implemented. The transmembrane voltage $\left(\mathrm{V}_{\mathrm{m}}\right)$ is calculated by the equation:

$$
C_{m} \frac{d V_{m}}{d t}+I_{\text {ion }}+I_{\text {stim }}=0 \text {, }
$$

where $C_{m}$ is the specific membrane capacitance $(100 \mathrm{pF})$, $\mathrm{I}_{\text {ion }}$ is the total ionic current that crosses the membrane and $\mathrm{I}_{\text {stim }}$ is the stimulus current.

\subsection{Models of gaseous air pollutants effects}

Based on experimental study [2], we established a relationship between the $\mathrm{CO}$ concentration and the decrease of the action potential duration (APD). The APD decrease is attributed to a blockage of the $\mathrm{I}_{\mathrm{CaL}}$ current. Thus, we developed a basic model of the $\mathrm{CO}$ effect on the $\mathrm{I}_{\mathrm{CaL}}$ current. The blocking factor of the $\mathrm{I}_{\mathrm{CaL}}$ current by $\mathrm{CO}$ $\left(b_{C O} C_{C a L}\right)$ is dependent on the concentration of $\mathrm{CO}\left(D_{C O}\right)$ through a linear relationship as follows: 


$$
b_{C O \_C a L}=0.0002 D_{C O}+0.0827,
$$

This equation was introduced on the $\mathrm{I}_{\mathrm{CaL}}$ equation of the cell model, and it was adjusted to obtain APD reductions that approximate those observed experimentally.

Using the Hill's equation, we developed concentrationdependent equations to simulate the $\mathrm{SO}_{2}$ effects on $\mathrm{I}_{\mathrm{CaL}}$, $\mathrm{I}_{\mathrm{Na}}, \mathrm{I}_{\mathrm{to}}$ and $\mathrm{I}_{\mathrm{K} 1}$. Based on an experimental study [10], the mathematical relationship between the concentration of $\mathrm{SO}_{2}$ and the blocking of the current $\mathrm{I}_{\mathrm{CaL}}\left(b_{\mathrm{SO}_{2} \mathrm{CaL}}\right)$ is as follows:

$$
b_{\mathrm{SO}_{2} \mathrm{CaL}}=\frac{1}{1+\left(\frac{35.99}{D_{S O_{2}}}\right)},
$$

where $\mathrm{D}_{\mathrm{SO}_{2}}$ is the $\mathrm{SO}_{2}$ concentration in $\mu \mathrm{M}$. The equations relating the increment of the $\mathrm{I}_{\mathrm{Na}}, \mathrm{I}_{\mathrm{K} 1}$ and $\mathrm{I}_{\mathrm{to}}$ currents due to $\mathrm{SO}_{2}$ were developed according to experimental studies $[6$, 7] as follows:

$$
\begin{gathered}
e_{\mathrm{SO}_{2} \mathrm{~N} a}=\frac{0.841}{1+\left(\frac{10.97}{D_{S O_{2}}}\right)}, \\
e_{\mathrm{SO}_{2} \mathrm{~K} 1}=\frac{1.07}{1+\left(\frac{28.5}{D_{S O_{2}}}\right)}, \\
e_{\mathrm{SO}_{2 \_} \mathrm{to}}=\frac{1}{1+\left(\frac{17}{D_{S O_{2}}}\right)},
\end{gathered}
$$

In agreement with experimental data [8], the mathematical relationship between the concentration of $\mathrm{NO}$ and the blocking of the current $\mathrm{I}_{\mathrm{Na}}$ is the following:

$$
b_{N O \_N a}=\frac{1}{1+\left(\frac{523}{D_{N O}}\right)^{6.8}},
$$

where $\mathrm{D}_{\mathrm{NO}}$ is the $\mathrm{NO}$ concentration in $\mathrm{nM}$. To simulate the effect of the NO on the $\mathrm{I}_{\mathrm{CaL}}$ current, the Michaelis-Menten equation was implemented as follows:

$$
e_{N O_{C a L}}=\frac{0.59\left(D_{N O}\right)}{D_{N O}+0.007},
$$

where the values $0.59 \mathrm{nM}$ and $0.007 \mathrm{nM}$ are the values of $e_{\max }$ and $\mathrm{EC}_{50}$ respectively. These equation was fitted using human atrial myocytes data from [7]. The factors (1 $\left.b_{\mathrm{CO} \_\mathrm{CaL}}\right),\left(1-b_{\mathrm{SO}_{2} \mathrm{CaL}}\right),\left(1+e_{\mathrm{SO} 2_{-} \mathrm{Na}}\right),\left(1+e_{\mathrm{SO} 2_{-} \mathrm{KI}}\right)$ and $(1+$ $\left.e \mathrm{SO}_{-} t_{\mathrm{o}}\right)$ were introduced to the $\mathrm{I}_{\mathrm{CaL}}, \mathrm{I}_{\mathrm{Na}}, \mathrm{I}_{\mathrm{K} 1}$ and $\mathrm{I}_{\mathrm{to}}$ equations in the cell model, respectively:

$$
\begin{gathered}
I_{C a L}=\left(1-b_{C O_{C a L}}\right)\left(1-b_{S O_{2}}\right)\left(1+e_{N O_{C a L}}\right) g_{C a L} d f f_{C a}\left(V_{m}\right. \\
-65), \quad(9) \\
I_{N a}=\left(1+e_{S O_{2 N a}}\right)\left(1-b_{N O_{N a}}\right) g_{N a} m^{3} h j\left(V_{m}-E_{N a}\right), \quad \text { (10) }
\end{gathered}
$$

$$
\begin{gathered}
I_{K 1}=\frac{\left(1+e_{S O_{2} K 1}\right) g_{K 1}\left(V_{m}-E_{K 1}\right)}{1+e^{0.07(V+80)}}, \\
I_{t o}=\left(1+e_{S O_{2 t o}}\right) g_{t o} O a^{3} o i\left(V_{m}-E_{t o}\right),
\end{gathered}
$$

\subsection{D model of human atrial tissue and electrical propagation}

A 2D model of human atrial tissue was developed through a $6 \times 6 \mathrm{~cm}$ matrix, discretized at a spatial resolution of $312.5 \mu \mathrm{m}$, obtaining a square mesh of $192 \times 192$ elements. The monodomain model, defined by the reaction-diffusion equation, describes the electrical propagation of the action potential wave in the tissue:

$$
\frac{1}{S_{v}} \nabla \cdot\left(D \nabla V_{m}\right)=C_{m} \frac{\delta V_{m}}{\delta t}+I_{\text {ion }}+I_{\text {stim }},
$$

where $\mathrm{S}_{\mathrm{v}}$ is the surface/volume ratio, $D$ is the conductivity tensor. The equation (13) was solved using a semi-spectral

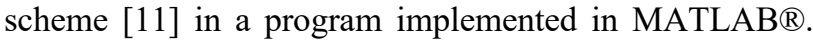
The tissue was considered isotropic. A conductivity of 0.4 $\mathrm{S} / \mathrm{cm}$ was assigned in order to obtain a conduction velocity of $62.5 \mathrm{~cm} / \mathrm{s}$.

\subsection{Simulation protocol}

We implemented the unicellular model to simulate the atrial action potential. Forward Euler method with a time step of $0.001 \mathrm{~ms}$ was implemented to solve temporal derivatives. A train of 10 stimuli was applied at a basic cycle length of $1000 \mathrm{~ms}$. The APD at $90 \%$ of the repolarization $\left(\mathrm{APD}_{90}\right)$ and the different currents were measured on the 10th beat.

The S1-S2 cross-field protocol was applied to the 2D model in order to initiate a rotor. The $\mathrm{S} 1$ stimulus generates a planar wave and it was applied at the left boundary of the model. The $\mathrm{S} 2$ stimulus is a square $(3 \mathrm{~cm} \times 3 \mathrm{~cm})$ and was applied after $\mathrm{S} 1$ at a corner of the model.

The $\mathrm{CO}$ and $\mathrm{SO}_{2}$ concentrations varying from 0 to 1000 $\mathrm{uM}$ and $\mathrm{NO}$ concentration varying from 0 to $500 \mathrm{nM}$ were implemented. Six cases were generated by combining the gaseous air pollutants concentrations as shown in Table 1.

Table 1. Combinations of gaseous air pollutants concentrations.

\begin{tabular}{cccc}
\hline Case & {$[\mathrm{CO}]$} & {$\left[\mathrm{SO}_{2}\right]$} & {$[\mathrm{NO}]$} \\
\hline $\mathrm{C} 1$ & $0 \mu \mathrm{M}$ & $0 \mu \mathrm{M}$ & $0 \mathrm{nM}$ \\
$\mathrm{C} 2$ & $200 \mu \mathrm{M}$ & $5 \mu \mathrm{M}$ & $1 \mathrm{nM}$ \\
$\mathrm{C} 3$ & $400 \mu \mathrm{M}$ & $50 \mu \mathrm{M}$ & $10 \mathrm{nM}$ \\
$\mathrm{C} 4$ & $600 \mu \mathrm{M}$ & $100 \mu \mathrm{M}$ & $100 \mathrm{nM}$ \\
$\mathrm{C} 5$ & $800 \mu \mathrm{M}$ & $500 \mu \mathrm{M}$ & $300 \mathrm{nM}$ \\
$\mathrm{C} 6$ & $1000 \mu \mathrm{M}$ & $1000 \mu \mathrm{M}$ & $500 \mathrm{nM}$ \\
\hline
\end{tabular}




\subsection{Phase singularity analysis}

The rotor tip motion is defined through phase singularity analysis. A phase map is generated by calculating the Hilbert transform of the membrane potential time series. The singularity is defined as the point where the phases, from $-\pi$ to $\pi$, converge and it is estimated through the topological charge density method [12].

\section{Results}

Under normal physiological conditions, an APD shortening was observed by increasing the concentrations of gaseous air pollutants, which was accentuated for $\mathrm{C} 3$. For $\mathrm{C} 2$, a slight increase of the plateau phase was observed. Under the highest concentration (C6), the magnitude of the maximum $\mathrm{I}_{\mathrm{CaL}}$ peak decreased by $95 \%(-21 \mathrm{pA})$, the $\mathrm{I}_{\mathrm{Na}}, \mathrm{I}_{\mathrm{to}}$ and $\mathrm{I}_{\mathrm{K} 1}$ peaks increased by $43 \%$ (-10300 pA), 96\% (100 $\mathrm{pA})$ and $61 \%(1440 \mathrm{pA})$ respectively, generating a significant decrease in the APD. The APD 90 reaches a value of $61 \mathrm{~ms}$, equivalent to a reduction of $81 \%$. The resting membrane potentials did not change significantly.

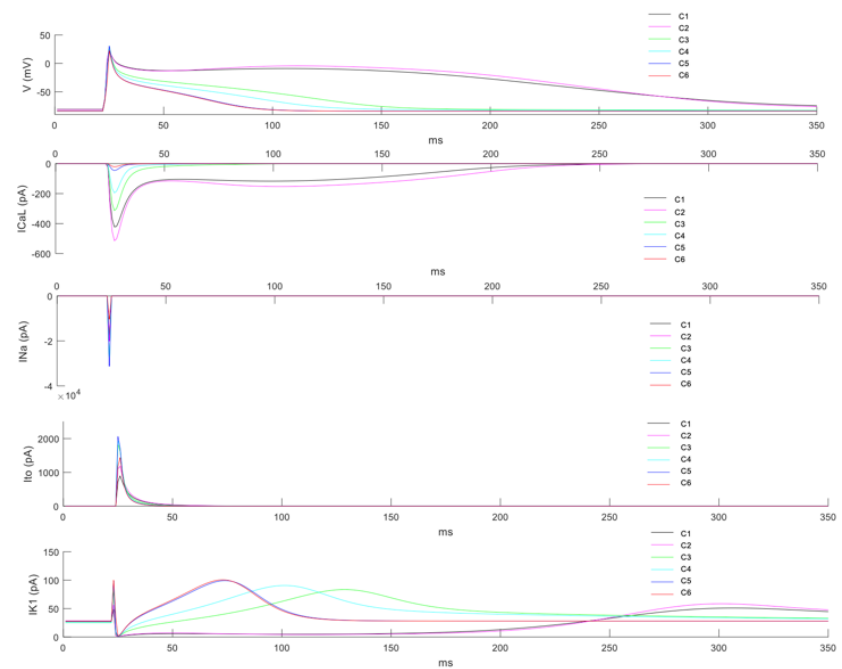

Figure 1. Atrial action potential and $\mathrm{I}_{\mathrm{CaL}}, \mathrm{I}_{\mathrm{Na}}, \mathrm{I}_{\mathrm{to}}$ and $\mathrm{I}_{\mathrm{K} 1}$ currents at concentrations corresponding to $\mathrm{C} 6$.

Table 2. Values of $\mathrm{APD}_{90}$ and percentage of reduction for the 6 cases of combinations of gaseous air pollutants concentrations.

\begin{tabular}{ccc}
\hline Case & APD $_{\mathbf{9 0}}(\mathbf{m s})$ & Reduction $(\mathbf{\%})$ \\
\hline C1 & 314 & 0 \\
C2 & 305 & 3 \\
C3 & 126 & 60 \\
C4 & 97 & 69 \\
C5 & 63 & 80 \\
C6 & 61 & 81 \\
\hline
\end{tabular}

The Table 2 shows the values of $\mathrm{APD}_{90}$ for the six cases of combination of gaseous air pollutants concentrations. An increase in the concentration of the gases causes a decrease in the APD, presenting a pronounced shortening from $\mathrm{C} 3$.

By applying the S1-S2 cross-field protocol to the 2D model, it was not possible to generate rotors for $\mathrm{C} 1, \mathrm{C} 2$ and C3. Under such conditions, the wavefront generated by S2 turns on itself, but it collides with its own refractory tail (unexcitable tissue) and it extinguishes, because the refractory period is greater than the turning trajectory.

On the other hand, when we applied gaseous air pollutants concentrations of $\mathrm{C} 4$ to $\mathrm{C} 6$, it was possible to generate stable rotors within vulnerable windows ranging from 34 for $\mathrm{C} 4$, to $42 \mathrm{~ms}$ for $\mathrm{C} 6$. The wavefront (having a shorter refractory period) encounters excitable tissue and continues to turn on itself, generating a stable rotor in the tissue. The rotor tip remains practically at the middle of the tissue. The Figure 2A depicts the rotor sequence obtained by applying the concentrations established in $\mathrm{C} 6$ to a coupling interval of $107 \mathrm{~ms}$ (corresponding to the middle value of the vulnerable window).

The phase singularity trajectory, that represents the temporal evolution of the rotor tip in the space, indicates high stability, where the core zone has about $0.9 \mathrm{~cm}$ of diameter (Figure 2B).

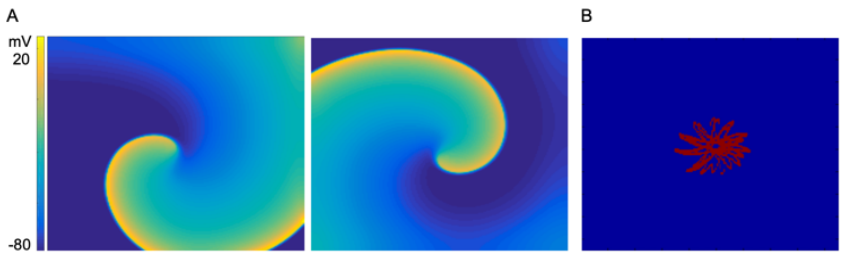

Figure 2. (A) Rotor and (B) phase singularity trajectory generated under $\mathrm{C} 6$ conditions.

\section{Discussion}

The simulation of the combined effects of $\mathrm{CO}, \mathrm{SO}_{2}$ and NO pollutant gases on the $\mathrm{I}_{\mathrm{CaL}}, \mathrm{I}_{\mathrm{Na}}, \mathrm{I}_{\mathrm{to}}$ and $\mathrm{I}_{\mathrm{K} 1}$ currents, showed a significant decrease in APD. At the highest simulated concentrations, the APD reaches up to $81 \%$ of reduction under normal physiological conditions. These results suggest a severe pro-arrhythmic effect. Clinical studies have shown that air pollution increases the risk of mortality from cardiovascular disease by $76 \%$ [13], deaths are mainly related to ischemia, arrhythmias and heart failure [14]-[16]. Strong evidence has been found about that mild exposure to high levels of air pollution increases mortality in patients with heart problems. Likewise, it has been demonstrated that prolonged exposures reduce the quality of life of people, and high air pollution increases hospital admissions for cardiovascular diseases [17]. 
Recent studies have shown a higher probability of the occurrence of cardiac arrhythmias after exposure to air pollutants, concluding that air pollution is an acute "trigger" of these arrhythmias [18]. Despite the existence of studies on the effects of air pollutants on the cardiovascular system, the mechanisms underlying the effects of acute and chronic exposure to these in the heart are not well established.

In a recent study [19], the effect of CO on the ventricular cell by computational simulation was assessed. It is important to highlight that, to date, there are few in silico studies that have evaluated the effect of air pollution on the cardiac system. Computational studies, as the one presented in this work, can contribute to a better understanding of the mechanisms by which these pollutants have harmful effects on cardiac tissue.

\section{Conclusion}

Our results show pro-arrhythmic effects of gaseous air pollutants on expressed through APD shortening and a rotor generation, during normal electrophysiological conditions.

\section{Acknowledgments}

This work was supported by COLCIENCIAS (Departamento Administrativo de Ciencia, Tecnología e Innovación) in Colombia, through grant No. 120677757994 and by the Dirección General de Política Científica de la Generalitat Valenciana (PROMETEO 2016/088).

\section{References}

[1] United Nations Environment Programme, "Air pollution: World's worst environmental health risk," in UNEP Year Book 2014: Emerging Issues in Our Global Environment, 2014

[2] D. V Abramochkin, N. N. Haertdinov, M. V Porokhnya, A. L. Zefirov, and G. F. Sitdikova, "Carbon monoxide affects electrical and contractile activity of rat myocardium," $J$. Biomed. Sci., vol. 18, no. 1, p. 40, 2011.

[3] R.-Y. Zhang et al., "Sulfur dioxide derivatives depress Ltype calcium channel in rat cardiomyocytes," Clin. Exp. Pharmacol. Physiol., vol. 38, no. 7, pp. 416-22, 2011.

[4] A. Nie and Z. Meng, "Modulation of L-type calcium current in rat cardiac myocytes by sulfur dioxide derivatives," Food Chem. Toxicol., vol. 44, no. 3, pp. 355363, 2006.

[5] A. Nie and Z. Meng, "Study of the interaction of sulfur dioxide derivative with cardiac sodium channel," Biochim Biophys Acta. vol. 1718, pp. 67-73, 2005.

[6] A. Nie and Z. Meng, "Sulfur dioxide derivative modulation of potassium channels in rat ventricular myocytes," Arch. Biochem. Biophys., vol. 442, no. 2, pp. 187-195, 2005.

[7] M. Kirstein, M. Rivet-Bastide, S. Hatem, A. Bénardeau, J.
Mercadirer, and R. Fischmeister, "Nitric oxide regulates the calcium current in isolated human atrial myocytes," $J$. Clin. Invest., vol. 95, no. 2, pp. 794-802, 1995.

[8] G. Ahmmed, Y. Xu, P. Hong Dong, Z. Zhao, J. Eiserich, and N. Chiamvimonvat, "Nitric oxide modulates cardiac $\mathrm{Na}+$ channel via protein kinase A and protein kinase G," Circ. Res., vol. 89, pp. 1005-1013, 2001.

[9] M. Courtemanche, R. J. Ramirez, and S. Nattel, "Ionic mechanisms underlying human atrial action potential properties: insights from a mathematical model.," Am. J. Physiol., vol. 275, pp. H301-H321, 1998.

[10] A. Nie and Z. Meng, "Modulation of L-type calcium current in rat cardiac myocytes by sulfur dioxide derivatives.," Food Chem. Toxicol., vol. 44, no. 3, pp. 355363, 2006

[11] J. Ugarte, C. Tobón, and A. Orozco-Duque, "Entropy mapping approach for functional reentry detection in atrial fibrillation: an in-silico study," Entropy, vol. 21, no. 2, pp. 194, 2019

[12] M. A. Bray, S. F. Lin, R. R. Aliev, B. J. Roth, and J. P. Wikswo, "Experimental and theoretical analysis of phase singularity dynamics in cardiac tissue.," $J$. Cardiovasc. Electrophysiol., vol. 12, no. 6, pp. 716-722, 2001.

[13] K. A. Miller et al., "Long-term exposure to air pollution and incidence of cardiovascular events in women," N. Engl. J. Med., vol. 356, no. 5, pp. 447-458, 2007.

[14] A. Peters, D. W. Dockery, J. E. Muller, and M. A. Mittleman, "Increased particulate air pollution and the triggering of myocardial infarction," Circulation, vol. 103 , no. 23, pp. 2810-2815, 2001.

[15] S. A. Glantz, "Air pollution as a cause of heart disease. Time for action," J. Am. Coll. Cardiol., vol. 39, no. 6, pp. 943-945, 2002.

[16] G. D. Thurston et al., “Ambient particulate matter air pollution exposure and mortality in the NIH-AARP diet and health cohort," Environ. Health Perspect., vol. 124, no. 4, pp. 484-490, 2016.

[17] D. Atkinson, T. Sim, and J. Grant, "Sodium metabisulfite and $\mathrm{SO} 2$ release: an under-recognized hazard among shrimp fishermen.," Ann. Allergy, vol. 71, no. 6, pp. 563566,1993

[18] C. R. Henry, D. Satran, B. Lindgren, C. Adkinson, C. I. Nicholson, and T. D. Henry, "Myocardial injury and longterm mortality following moderate to severe carbon monoxide poisoning," Am. Med. Assoc., vol. 295, no. 4, pp. 398-402, 2006.

[19] B. Trenor, K. Cardona, J. Saiz, S. Rajamani, L. Belardinelli, and W. R. Giles, "Carbon monoxide effects on human ventricle action potential assessed by mathematical simulations," Front. Physiol., vol. 4, p. 282, 2013.

Address for correspondence:

Catalina Tobón Zuluaga.

Universidad de Medellín

Cra. 87 \#30-65, Medellín, Colombia

ctobon@udem.edu.co 